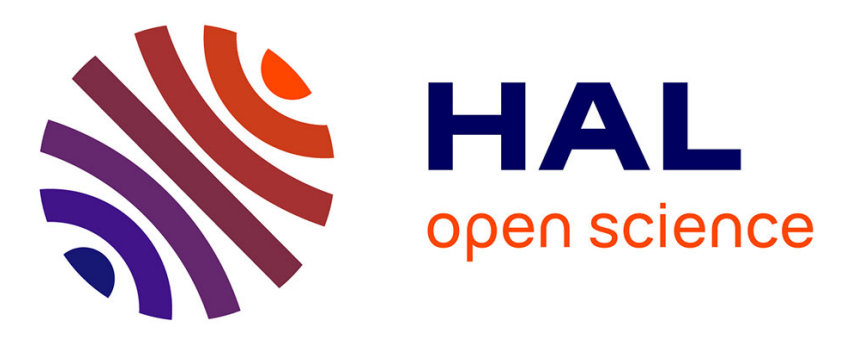

\title{
Small p53 derived peptide suitable for robust nanobodies dimerization
}

Frank Dietsch, Yves Nominé, Audrey Stoessel, Camille Kostmann, Anna Bonhoure, Bruno Chatton, Mariel Donzeau

\section{- To cite this version:}

Frank Dietsch, Yves Nominé, Audrey Stoessel, Camille Kostmann, Anna Bonhoure, et al.. Small p53 derived peptide suitable for robust nanobodies dimerization. Journal of Immunological Methods, 2021, 498, pp.113144. 10.1016/j.jim.2021.113144 . hal-03370331

\section{HAL Id: hal-03370331 \\ https://hal.science/hal-03370331}

Submitted on 7 Oct 2021

HAL is a multi-disciplinary open access archive for the deposit and dissemination of scientific research documents, whether they are published or not. The documents may come from teaching and research institutions in France or abroad, or from public or private research centers.
L'archive ouverte pluridisciplinaire $\mathbf{H A L}$, est destinée au dépôt et à la diffusion de documents scientifiques de niveau recherche, publiés ou non, émanant des établissements d'enseignement et de recherche français ou étrangers, des laboratoires publics ou privés. 


\title{
Small p53 derived peptide suitable for robust nanobodies dimerization
}

\author{
Frank Dietsch ${ }^{1}$, Yves Nominé $^{2}$, Audrey Stoessel ${ }^{1}$, Camille Kostmann ${ }^{2}$, Anna Bonhoure $^{2}$, Bruno \\ Chatton $^{1}$ and Mariel Donzeau ${ }^{1 *}$. \\ 1 Université de Strasbourg, UMR7242 Biotechnologie et Signalisation Cellulaire, Ecole \\ Supérieure de Biotechnologie Strasbourg, F-67412 Illkirch, France. \\ ${ }^{2}$ Institut de Génétique et de Biologie Moléculaire et Cellulaire, Illkirch, F-67412 IIlkirch, \\ France. \\ *mariel.donzeau@unistra.fr
}

KEY WORDS: $\mathrm{V}_{\mathrm{H}} \mathrm{Hs}$, bivalency, dimerization domain, peptide, p53, avidity

\begin{abstract}
Bivalent $\mathrm{V}_{\mathrm{H}} \mathrm{Hs}$ have been shown to display better functional affinity compared with their monovalent counterparts. Bivalency can be achieved either by inserting a hinge region between both $\mathrm{V}_{\mathrm{H}} \mathrm{Hs}$ units or by using modules that lead to dimerization. In this report, a small self-associating peptide originating from the tetramerization domain of p53 was developed as a tool for devicing nanobody dimerization. This E3 peptide was evaluated for the dimerization of an anti-eGFP nanobody (nano-eGFP-E3) whose activity was compared to a bivalent antieGFP constructed in tandem using GS rich linker. The benefit of bivalency in terms of avidity and specificity was assessed in different in vitro and in cellulo assays. In ELISA and SPR, the dimeric and tandem formats were nearly equivalent in terms of gain of avidity compared to the monovalent counterpart. However, in cellulo, the nano-eGFP-E3 construct showed its superiority over the tandem format in terms of specificity with a highest and better ratio signalto-noise. All together, the E3 peptide provides a universal suitable tool for the construction of dimeric biomolecules, in particular antibody fragments with improved functional affinity.
\end{abstract}

\section{INTRODUCTION}

Nanobodies $\left(\mathrm{V}_{\mathrm{H}} \mathrm{Hs}\right)$ are valuable tools for various applications, which are directly linked to their small size, outstanding stability and solubility, and their capacity to fold in a reducing environment (De Meyer et al., 2014; Dumoulin et al., 2002; Muyldermans, 2013). For example, two innovative developments for research are chromobodies as tracers for in vivo intracellular targets and immunomodulators to interfere in vivo with protein functions or 
localization (Rothbauer et al., 2006). For diagnostic, $\mathrm{V}_{\mathrm{H}} \mathrm{Hs}$ labeled with a radionuclide are applied as detection tracers (De Meyer et al., 2014).

$\mathrm{V}_{\mathrm{H}} \mathrm{Hs}$ are monovalent, possessing only one paratope binding capacity. However, multivalency, which is a general nature of antibodies, increases the apparent affinity compared to monovalent molecules for binding to "repeated" epitopes or to surface-bound antigens (Donzeau and Knappik, 2007; Pack et al., 1992; Rheinnecker et al., 1996). Therefore, bivalency might be advantageous or even crucial for particular applications. Converting a $\mathrm{V}_{\mathrm{H}} \mathrm{H}$ into bivalent format can dramatically increase its potencies and binding capacities when compared to the related monovalent counterpart (Beirnaert et al., 2017; Coppieters et al., 2006; De Vlieger et al., 2019; Klooster et al., 2009). Indeed, an engineered bivalent $\mathrm{V}_{\mathrm{H}} \mathrm{H}$ directed against the trimeric envelope protein of the Respiratory Syncytial Virus (RSV) neutralized the RSV Long strain about 4000-fold better than the monovalent format (Hultberg et al., 2011), and the conversion of a human TNF-specific $\mathrm{V}_{\mathrm{H}} \mathrm{H}$ binder into bivalent format enhanced its neutralizing potency up to 400 -fold (from nM to $\mathrm{pM}$ range)(Coppieters et al., 2006).

Bivalent formats are generally achieved by using linkers of various length generally introduced by genetic engineering, creating $\mathrm{V}_{\mathrm{H}} \mathrm{H}$ in tandems. DNA sequences coding either for hinge regions composed of glycine and serine residues or for the natural IgG2c hinge of llama heavy-chain antibodies, are inserted between the two $\mathrm{V}_{\mathrm{H}} \mathrm{H}$ coding sequences (De Vlieger et al., 2019; Els Conrath et al., 2001; Rothbauer et al., 2006) producing a tail-to-head fusion format. Another way of managing bivalency is the addition of a dimerization tag or domain, such as GCN4 or IgG Fc (Cardoso et al., 2014; De Meyer et al., 2014; Saerens et al., 2008) in the $\mathrm{C}$-terminal domain of the $\mathrm{V}_{\mathrm{H}} \mathrm{H}$, given rise to a tail-to-tail format. The last way is by chemical conjugation (van Lith et al., 2017). All three methods have been used successfully.

We have recently taken advantage of a modified tetramerization domain of p53 to construct bifunctional and bispecific heterotetramer biomolecules (Stoessel et al., 2020; Vigneron et al., 2019). This tetramerization domain (p53tet) is a small peptide of 31-aminoacids, which can be fused to various moieties. In this work, we use the mutant p53tetE343K/E346K (hereinafter referred to as E3), where two lysine residues were mutated in glutamic acid residues, enabling to exclusively form an homodimer extremely stable in vitro and in cellulo (Brokx et al., 2003). We demonstrate that compared to tandem linked bivalent $\mathrm{V}_{\mathrm{H}} \mathrm{H}$, such a homodimer discloses the same and even improves biophysical properties in term of solubility, avidity and stability in living cells.

\section{MATERIAL AND METHODS}

\section{Cell Lines}

U2OS, H2B-eGFP HeLa cells and MRC5 YFP-poln cells were maintained as monolayer in Dulbecco's modified Eagle's medium (DMEM) supplemented with $4.5 \mathrm{~g} / \mathrm{L}$ glucose, $10 \%$ fetal 
calf serum (FCS) and $1 \mathrm{mM}$ pyruvate. Cells were transiently transfected with expression plasmids using JetpEI reagent (Polyplus transfection, Illkirch) according to the manufacturer's protocol or electro-transfected with proteins as previously described (Freund et al., 2013).

\section{Recombinant plasmid constructions}

DNA sequences encoding for nano-eGFP were synthetized by Integrated DNA Technologies (IDT), amplified by PCR using oligonucleotides: nano-forward CGTCAGCCATGGGGTCCCAGGTTCAGC and nano-reversed CCACAGGAATTCACAATGGTGATGATGGTGATGTGCG. They were then inserted either into pETOM digested by Ncol-EcoRI or into the pET-con1-E3 digested with Ncol-Spel described elsewhere (Vigneron et al., 2019) given rise to the pETOM-nano-eGFP-mono and pETOMnano-eGFP-E3 expression vectors, respectively. For the pETOM-nano-eGFP-tandem, an optimized sequence encoding the nano-eGFP followed by $(\mathrm{G} 4 \mathrm{~S})_{3}$ linker was synthetized by Integrated DNA Technologies (IDT), amplified by PCR using forward GGATCCCCATGGGTTCTCAG and reverse CAATTGCCATGGAAGAACCGC oligonucleotides, and cloned into the pETOM-nano-eGFP-mono digested by Ncol giving rise to pETOM-nano-eGFP-tandem.

To generate eukaryotic expression vectors used in this study, the nano-eGFP fused or not to E3 sequence, and the nano-eGFP-tandem coding sequences were first amplified by PCR from pETOM-nano-eGFP-mono, pETOM-nano-eGFP-E3 and pETOM-nano-eGFPtandem vectors, respectively using the described primers. The fragments were digested with Ncol and Spel restriction enzyme, and cloned into the pßA-based vector (Vigneron et al., 2019). A doubled-stranded DNA sequence oligonucleotide encoding an avitag GLNDIFEAQKIEWHE, was cloned in Ndel site of the pET-Histag-eGFP. Sequences of DNA constructs were verified by DNA sequencing. The $\beta$-Gal-eGFP, $\beta$-Gal-NLS-eGFP, P40M1-eGFP-con1 and YFP-DNA polymerase $\eta$ expression plasmids have been described elsewhere

(Baldeck et al., 2015; Freund et al., 2014; Masson et al., 2003; Shima et al., 1997; Vigneron et al., 2019). The doubled-stranded DNA sequence oligonucleotide encoding a mitochondriatargeting signal (MTS) MISLTARLSRSAPDSQACYSV-LGAFLGKCADV was cloned between the HindlII and the Pstl sites of pEGFP-N1 vector.

\section{Expression and purification of the recombinant fusion proteins}

Briefly, eGFP, avitag-eGFP, and the nanobodies were expressed in E. coli BL21 (DE3) pLysS by induction with $1 \mathrm{mM}$ IPTG at $20{ }^{\circ} \mathrm{C}$ overnight. Proteins were purified on HiTrap IMAC resin $(1 \mathrm{ml})$ saturated with nickel or cobalt (GE Healthcare Saclay, France) and subsequently loaded on HiLoad 16/600 75 prep grade column (GE Healthcare, Bio-sciences $A B$, sweden) operating at a flow rate of $0.5 \mathrm{ml} / \mathrm{min}$. Fractions were separated on SDS-PAGE gels and analyzed by Coomasie blue.

\section{Biotinylation of avitag-eGFP}


Typically, enzymatic biotinylation was performed with $50 \mathrm{mM}$ ATP (Adenosine triphosphate); $10 \mathrm{mM}$ Magnesium Acetate; $150 \mu \mathrm{M}$ d-biotin; $6 \mu \mathrm{g}$ BirA enzyme added to 500 $\mu g$ purified avitag-eGFP in solution in PBS $\times 1$. The mix was incubated for $48 \mathrm{~h}$ at $4^{\circ} \mathrm{C}$ and the biotinylated product was purified by SEC. Biotinylation efficiency was evaluated by incubating the biotinylated protein with saturating amount of streptavidin magnetic beads (GE Healthcare, Bio-sciences $A B$, sweden), thus, all biotinylated proteins bind the streptavidin and the amount of remaining proteins can be estimated by loading the supernatant on SDS-PAGE.

\section{Enzyme-linked immunosorbent assay (ELISA)}

Indirect ELISA, which usually involves two binding processes of primary antibody and secondary labeled antibody was modified as follow: Maxisorp microtiter plates (Nunc, Denmark) were coated with $20 \mu \mathrm{g} / \mathrm{ml}$ of recombinant PCNA in phosphate buffer, PBS, pH 8 , for $16 \mathrm{~h}$ at $4{ }^{\circ} \mathrm{C}$. Wells were blocked with $0.2 \mathrm{ml}$ of $2 \%(\mathrm{w} / \mathrm{v})$ milk in PBS, $\mathrm{pH} 7.4$, containing $0.1 \%(\mathrm{v} / \mathrm{v})$ of Tween-20 for $1 \mathrm{~h}$ at RT. A dilution series of purified tagged proteins was added to the pre-coated microtiter plates beginning with a concentration of $10 \mu \mathrm{M}$ and incubated $\mathrm{ON}$ at $4{ }^{\circ} \mathrm{C}$. After extensive washing with PBS, recombinant proteins were detected with a secondary c-myc 9E10 mouse antibody followed by a ternary peroxidase conjugated antimouse antibody (Dianova, Germany) at $2 \mu \mathrm{g} / \mathrm{ml}$. The signal was developed by addition of $100 \mathrm{\mu l} /$ well of TMB color reagent (sodium acetate $0.1 \mathrm{M}, \mathrm{pH} 6.6,0.1 \mathrm{mg} / \mathrm{ml}$ of 3, 3', 5, 5'tetramethylbenzidine (TMB), $2 \mu \mathrm{l}$ of $35 \%$ Hydrogen peroxide, and stopped with $50 \mu \mathrm{l}$ of sulfuric acid at $0.45 \mathrm{M}$. The signal was monitored with an ELISA plate reader (BioRad 550) at a wavelength of $450 \mathrm{~nm}$. Data were first processed with the dose-response curve (drc) package of the $\mathrm{R}$ language using the following four-parameter log-logistic function to determine the apparent $\mathrm{K}_{\mathrm{D}}: f(x)=\operatorname{Min}+\frac{\operatorname{Max}-\operatorname{Min}}{1+\left(\frac{K_{D}}{x}\right)^{b}}$, where $\mathrm{x}$ is the concentration.

\section{Surface Plasmon Resonance}

Protein-protein interaction assays were performed on a Biacore T200 instrument (Cytiva, Malborough, MA, USA) at $25{ }^{\circ} \mathrm{C}$ using PBS buffer $\mathrm{pH} 7.4$ supplemented with surfactant polysorbate 20 (Cytiva) $0.005 \%(\mathrm{v} / \mathrm{v}$ ) as running buffer. The biotin CAPture kit was used as previously described (Bonhoure et al., 2018), allowing the reverse capture of the biotinylated eGFP antigen. Briefly, in each cycle, a 5 -fold dilution solution of the CAPture reagent is injected on all four channels for $300 \mathrm{~s}$ at $2 \mu \mathrm{L} / \mathrm{min}$. One channel (harboring only CAPture reagent and no biotinylated peptide) was systematically defined as the reference flow cell to serve as a control for non-specific binding of the analyte. Biotinylated eGFP was immobilized by injecting a $100 \mathrm{nM}$ solution for 30,60 or $90 \mathrm{~s}$ contact time at $15 \mu \mathrm{L} / \mathrm{min}$ on distinct cells. One of the three nano-eGFP constructs was then injected as analyte on the four channels for $180 \mathrm{~s}$ at a flow rate of $80 \mu \mathrm{L} / \mathrm{min}$, followed by the dissociation phase for 240 additional 
seconds. At the end of each cycle, the surface was fully regenerated by injecting the regeneration solution ( $\mathrm{GdmCl} 6 \mathrm{M}, \mathrm{NaOH} 0.25 \mathrm{M}$ ) as indicated by the manufacturer.

Kinetic measurements were achieved by injecting a series of two-fold concentration of nanoeGFP constructs, in the $0.12-1000.0 \mathrm{nM}$ range, by increasing concentration order. The 2.0 and $62.5 \mathrm{nM}$ concentrations of the nano-eGFP constructs were systematically replicated the end of the concentration series in order to assess for reproducibility. All the assays were recorded for 3 different eGFP immobilization levels (roughly $\sim 60, \sim 180$ and $\sim 260 \mathrm{RU}$ ) related to the three different ligand contact time. Data for the shortest contact time, and therefore the lowest immobilization signal of eGST protein ( $\sim 60 \mathrm{RU})$, were considered for analysis in order to reduce the binding capacity of the surface and minimize the possible mass transport effects. Data were first processed using the Biacore T200 Evaluation 1.0 software (Cytiva) for correcting for the buffer effects and bulk refractive index changes, followed by an in-house Python script for automatically superimposing and dividing each sensorgram by the theoretical maximum normalized binding signal $R_{\text {max,norm }} R_{\text {max,norm }}$ was determined according to (Karlsson et al., 1997):

$R_{\max , \text { norm }}=\frac{M W_{\text {analyte }}}{M W_{\text {ligand }}} R_{\text {immob }}$

where MWanalyte and $M W_{\text {ligand }}$ are the molecular weights of the analytes and the biotinylated eGFP ligand (29.5 kDa), respectively, Rimmob is the immobilization level of the biotinylated-eGFP ligand. Here we assumed that the ligand owns one analyte binding site per ligand molecule and that the ligand is $100 \%$ active on the surface. Such a processing allows to directly compare sensorgrams obtained for monomers (nano-eGFP-mono and nano-eGFPtandem) or dimers (nano-eGFP-E3).

\section{Immunofluorescence}

Cells grown on coverslips were fixed with $4 \%(\mathrm{w} / \mathrm{v})$ paraformaldehyde for $30 \mathrm{~min}$ and then permeabilized with $0.2 \%$ Triton $X-100$ for $5 \mathrm{~min}$. In some experiments, the cells were treated with ice-cold cytoskeletal buffer (CSK: $10 \mathrm{mM} \mathrm{HEPES} \mathrm{pH} \mathrm{6.8,} 100 \mathrm{mM} \mathrm{NaCl}, 300 \mathrm{mM}$ sucrose, $3 \mathrm{mM} \mathrm{MgCl} 2,1 \mathrm{mM} \mathrm{EGTA}$ ) with $0.2 \%$ Triton-X100 for 5 min prior fixation. Cells were either observed by direct immunofluorescence or further incubated with the purified recombinant proteins in PBS at different concentrations. The recombinant proteins were then detected with the anti-c-Myc 9E10 monoclonal antibody (1/5000) followed by anti-mouse antibody conjugated with Alexa Fluor 568 (1/10000) (Life Technologies). Coverslips were mounted with Fluoromount G containing 4',6'-diamidino-2 phenyleindole (SouthernBiotech, Birmingham, UK). The treated cells were analyzed using conventional fluorescence microscopy with a Leica DM5500 microscope (Leica Microsystems, Wetzlar, Germany). Images were processed with Image J2.0.0.

\section{RESULTS:}


We use the well-characterized nanobody directed against the green fluorescent protein, eGFP, (cAbGFP4) referred herein as nano-eGFP-mono that has been described to have a $K_{D}$ measured by SPR of $0.32 \mathrm{nM}$ (Saerens et al., 2005). Bivalency was achieved either by genetically fusing the nano-eGFP coding sequence in a tandem with a spacer composed of four glycine residues followed by one serine repeated 3 times (hereinafter referred as to nanoeGFP-tandem), or via the self-associating peptide E3 (hereinafter refereed as to nano-eGFPE3), which originates from the tetramerization domain of p53 (residues 325-355) (Figure 1A) (Vigneron et al., 2019). The paratopes of these two bivalent nanobodies have a different orientation relatively to each other, namely a tail-to-head and a tail-to-tail orientation, respectively.

DNA Coding

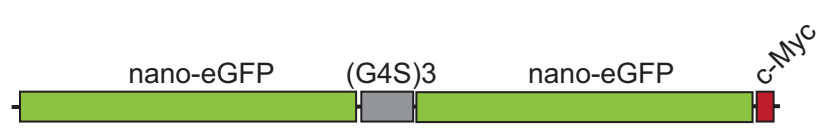

Schematic structure
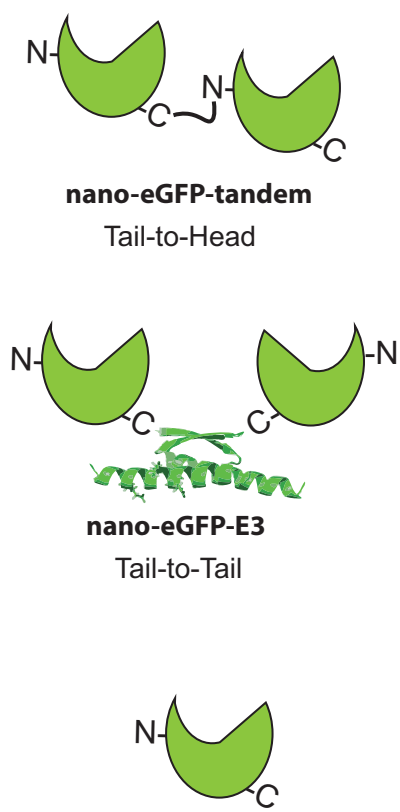

nano-eGFP-mono
MW

monomeric

Figure 1: Schematic representations of the nano-eGFP-tandem, nano-eGFP-E3 and nano-eGFP-mono. The structure of the tetramerization domain of p53 is depicted according to PDB1C26 (Jeffrey et al., 1995). The DNA sequences encoding each module are represented in the left panel (light green box for nano-eGFP, gray box for a GGGGS linker repeated 3 fold and dark green box for the E3 helix). The theoretical oligomerization states of the corresponding proteins with the expected molecular weights of each monomeric species are depicted on the right panel.

Recombinant proteins were expressed in E. coli. The nano-eGFP-mono, nano-eGFPtandem and nano-eGFP-E3 were produced at high levels (around $80 \mathrm{mg} / \mathrm{L}$ ) and were highly soluble with no notable difference between all three constructs (Figure S1). The three nanobodies were purified on immobilized metal affinity chromatography followed by a preparative size exclusion chromatography (Figure S2). Typical elution profiles revealed that the nano-eGFP-mono and the nano-eGFP-tandem behaved both as monomers, while the 
nano-eGFP-E3 displayed a single peak corresponding to a homodimer. The final yields of purified proteins were between 50 and $80 \mathrm{mg} / \mathrm{L}$.

Bivalency usually increases the apparent binding constant to surface-bound antigen. Thus, an indirect ELISA experiment was performed against a plastic-immobilized recombinant eGFP (Figure 2A). The nanobodies were detecting the eGFP, yet with different efficiencies. The apparent binding efficiencies of the dimers nano-eGFP-E3 and the nano-eGFP-tandem were moderately enhanced by about 10- and 7-fold as compared to the nano-eGFP-mono, respectively. Thus, dimerization in both cases leads to a modest gain of binding efficiency likely by means of avidity. Furthermore, the nano-eGFP-E3 and the nano-eGFP-tandem exhibit a fitted slope coefficient of the Hill function larger than one $(b=1.23 \pm 0.07$ and $1.13 \pm$ $0.07)$ as compared to $\mathrm{a} \mathrm{b}$ value for the nano-eGFP-mono below one, $(b=0.74 \pm 0.12)$, which is suggesting a positive cooperativity of the bivalent format for the surface-bound antigen (Table S1) (Syedbasha et al., 2016).

Biosensor Surface Plasmon Resonance (SPR) experiments were conducted to compare the binding kinetics of the three nanobodies for the eGFP-antigen immobilized on a CAP sensor chip (Figure 2B). Although none of the steady state or kinetic fits can be performed on the sensorgrams, kinetic traces revealed several interesting aspects of the interaction between the eGFP and the $\mathrm{V}_{\mathrm{H}} \mathrm{H}$ nanobodies. During the post-injection phase, the signal was almost constant over the time, suggesting a possible strong affinity but impeding binding kinetic rates estimation. Extending the dissociation time at a delay as long as $20 \mathrm{~min}$ did not lead to a significant lost of signal. Furthermore, curves obtained for the various concentrations of the different constructs remained almost parallel, suggesting the absence of significant visible differences on the dissociation rates $k_{\text {off }}$ of the three constructs. During the injection phase, the equilibrium state was not reached at the end of the phase for low analyte concentrations, impeding a steady-state analysis. Yet, such an analysis would have been interesting in order to compare with the indirect ELISA data, which are recorded at equilibrium due to the inherently long incubation time. Meanwhile, the theoretical maximal normalized response $R_{\text {max,norm }}$ (1.00) was reached for nano-eGFP-E3, although it was not attained for nano-eGFP-mono (plateau at $R_{\text {norm }} \sim 0.9$ ) for unclear reasons. The difference with $R_{\text {max,norm }}$ was even more pronounced for the nano-eGFP-tandem (plateau at $R_{\text {norm }} \sim 0.7$ ) as compared to the nano-eGFP-E3 homodimer. Nevertheless, the differential effect of the $\mathrm{V}_{\mathrm{H}} \mathrm{Hs}$ can be explored by comparing normalized sensorgrams obtained for a same concentration. A $2.0 \mathrm{nM}$ concentration value, in addition to belong to the range of apparent affinities determined by indirect ELISA assay, seems to be a good compromise to avoid high concentration values for which the sensorgrams display significant differences in curvature, and low values for which the signal increase is limited. With about $25 \%$ signal increase, the sensorgram comparison revealed a possible moderate gain of apparent affinity for nano-eGFP-tandem and nano- 
eGFP-E3 compared to the monomeric nano-eGFP-mono, confirming the results obtained by the indirect ELISA assay.

A

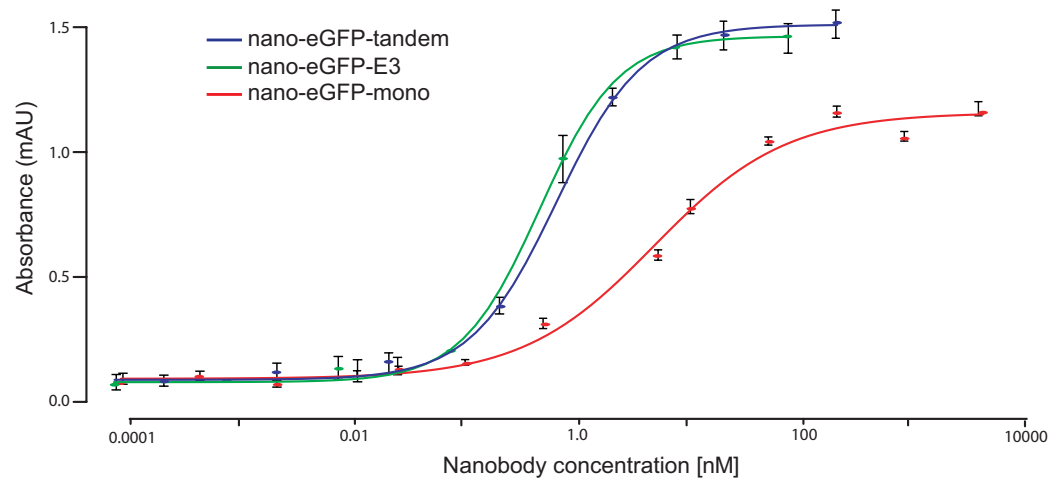

B

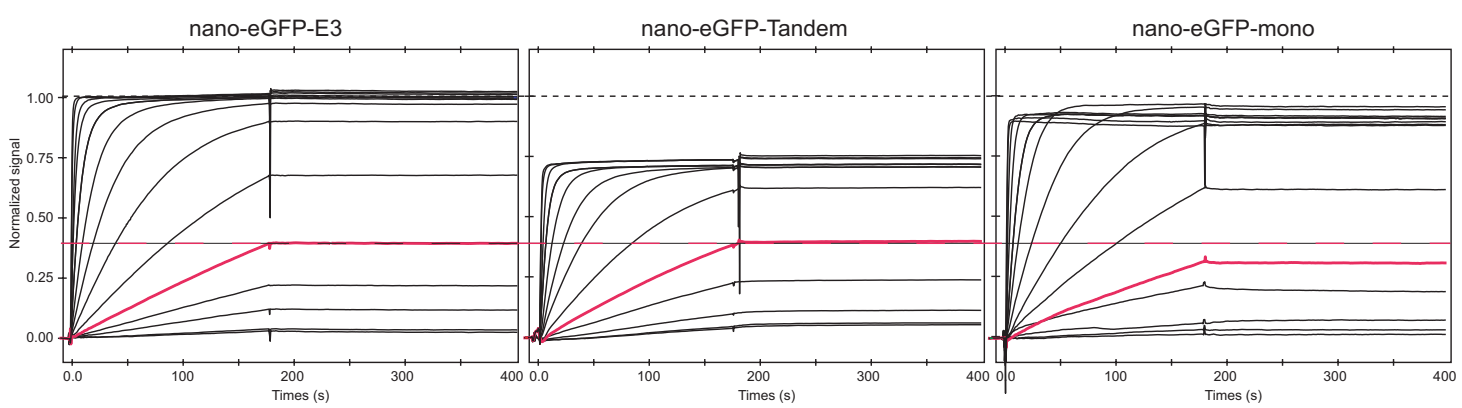

Figure 2: Functional binding properties of the nanobodies. (A). Apparent binding constants of the nanobodies based on valence concentration were measured by indirect ELISA against immobilized purified eGFP at a concentration of $2 \mu \mathrm{g} / \mathrm{ml}$. Binding curve averages of three independent experiments are shown. Apparent binding constant is $4.67 \pm 0.99 \mathrm{nM}$ for the nano-GFP-mono, $0.44 \pm 0.02 \mathrm{nM}$ for the nano-GFP-E3 and $0.63 \pm 0.04 \mathrm{nM}$ for the nano-eGFP-tandem. (B) Kinetics analysis of the nanobody interaction followed by Surface Plasmon Resonance. Are shown the normalized signal over time after double referencing. The normalized signal takes into account the immobilized ligand level and the analyte / ligand molecular weight ratio, and assumes a 1:1 binding model (by considering here the nanoeGFP-E3 as a homodimer, and the nano-eGFP-tandem and nano-eGFP-mono as monomeric species, each of them possibly interacting with a single eGFP partner). Such normalized sensorgrams allow to directly compared signal obtained for different valencies. Kinetic runs were performed by injecting series of two-fold cascade dilution of the nano-eGFP constructs between 0.12 and $1000 \mathrm{nM}$, in increasing order, i.e. a total of 14 distinct concentrations. Repeated sensorgrams (at 2.0 or $62.5 \mathrm{nM}$ ) do not reveal visible differences, confirming the good reproducibility of the assay. Sensor surface is regenerated after each cycle. The thin dotted black line corresponds to the theoretical maximal normalized response (1.00), while the dashed red line corresponds to the $R_{\text {norm }}$ signal attained by the nano-eGFP-E3 at the end of the injection phase.

The binding efficiencies of the nano-eGFP constructs were next evaluated by conventional immunofluorescence detection after fixation and permeabilization of the HeLa cells stably expressing the H2B-eGFP tagged protein (Rothbauer et al., 2006) (Figure 3). At $20 \mathrm{nM}$ and $4 \mathrm{nM}$, all three nano-GFP formats were detecting the endogenous nuclear $\mathrm{H} 2 \mathrm{~B}-$ 
eGFP with a better efficiency for the bivalent formats. At $0.8 \mathrm{nM}$, only the nano-eGFP-E3 was able to detect the H2B-eGFP. This result was unexpected as both constructs displayed very similar apparent affinity at equilibrium. Moreover, one should however note that at the $4 \mathrm{nM}$, while the nano-eGFP-E3 could clearly detect the chromatin-bound antigen, the nano-eGFPtandem detection already triggered a slight background increased.

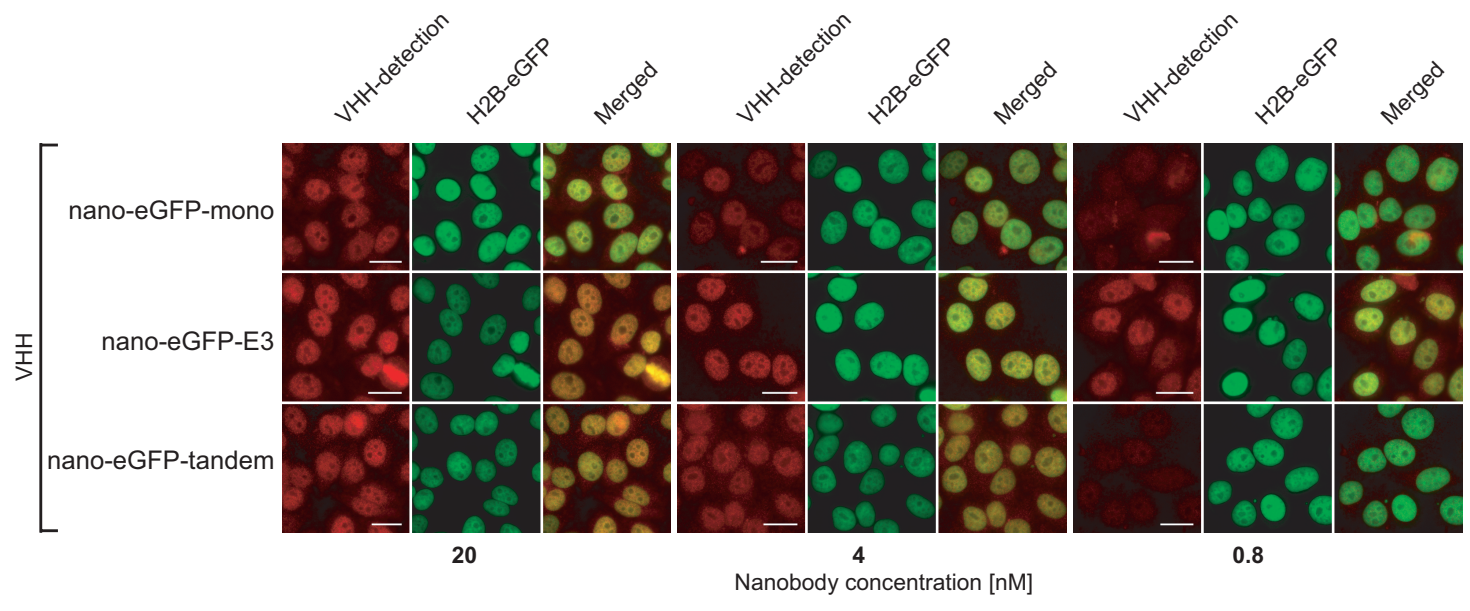

Figure 3. Detection of the eGFP in fixed and permeabilized HeLa cells stably expressing H2B-eGFP fusion protein by conventional immunofluorescence. The binding of the purified nanobodies to H2BeGFP was detected using the anti-Myc 9E10 monoclonal antibody (mAb) followed by goat anti-mouse Ab-conjugated with Alexa Fluor 568 (red). Scale bar $20 \mu \mathrm{m}$.

The ability of the three different nano-eGFP formats to bind to eGFP fusion proteins inside of living cells was then investigated on distinct eGFP fusion proteins localized in different cell compartments. (i) The $\beta$-galactosidase-eGFP either with a nuclear localization signal (NLS) enabling its nuclear transport or without, and therefore restricted to the cytoplasmic compartment was evaluated (Masson et al., 2003). (ii) Two eGFP-fusion proteins embedded in the chromatin consisting of the polymerase- $\eta$ fused to YFP (Baldeck et al., 2015) and a chimera (P40M1-eGFP-con1) binding strongly to the proliferating cell nuclear antigen (PCNA), a processivity factor of the replicative polymerases, were tested (Freund et al., 2014). (iii) Finally, the eGFP directed to the mitochondria compartment using a mitochondria-targeting sequence (MTS-eGFP) was also used.

The first strategy consisted to transiently co-transfect expression plasmids encoding the nanobodies and the eGFP-antigens in U2OS cells (Figure 4AB). The nanobodies were revealed using a monoclonal anti-c-Myc antibody followed by a fluorescent anti-mouse antibody and the eGFP-antigen was visualized by direct immunofluorescence. All three nanoeGFP formats were able to bind to the eGFP fusion proteins, yet with different binding efficiencies. Monovalent and bivalent formats were clearly sequestered in the cytoplasm through their binding to $\beta$-galactosidase-eGFP, while the negative control, nano-Lamin, was freely diffusing into the nucleus, and thus distributed in both compartments (Figure 4A). Conversely, both bivalent $\mathrm{V}_{\mathrm{H}} \mathrm{Hs}$ were distributed exclusively in the nucleus when co- 
transfected with eGFP-NLS- $\beta$-Galactosidase, while the monovalent were slightly detected in the cytoplasm (Figure 4A).

To detect the chimera (P40M1-eGFP-con1), which strongly interacts with PCNA tightly bound to the chromatin (Moldovan et al., 2007), cells were treated or not with cytoskeletal buffer (CSK) prior fixation (Figure 4B and Figure S3). CSK treatment removes freely and loosely held proteins in order to reveal only PCNA molecules at replication foci. Without CSK treatment, as the amount of the $\mathrm{V}_{\mathrm{H}} \mathrm{Hs}$ is exceeding the chromatin-bound PCNA, it was not possible to clearly detect PCNA foci (Figure S3). However, with CSK treatment, the foci corresponding to chromatin-bound PCNA were then revealed by all three nanobodies while with different efficiencies (Figure 4B). Indeed, the nano-GFP-E3 and the nano-GFP-tandem were distinctly better at detecting PCNA foci than the nano-GFP-mono, leading to high background level.

Finally, as the MTS-eGFP is a soluble antigen, no CSK treatment could be applied. The detection by all three nanobodies was not successful and led to a blurry signal (Figure S4). Nevertheless, these results confirmed the similar avidity effect of both bivalent nanoeGFP in regard to the monovalent counterpart. 

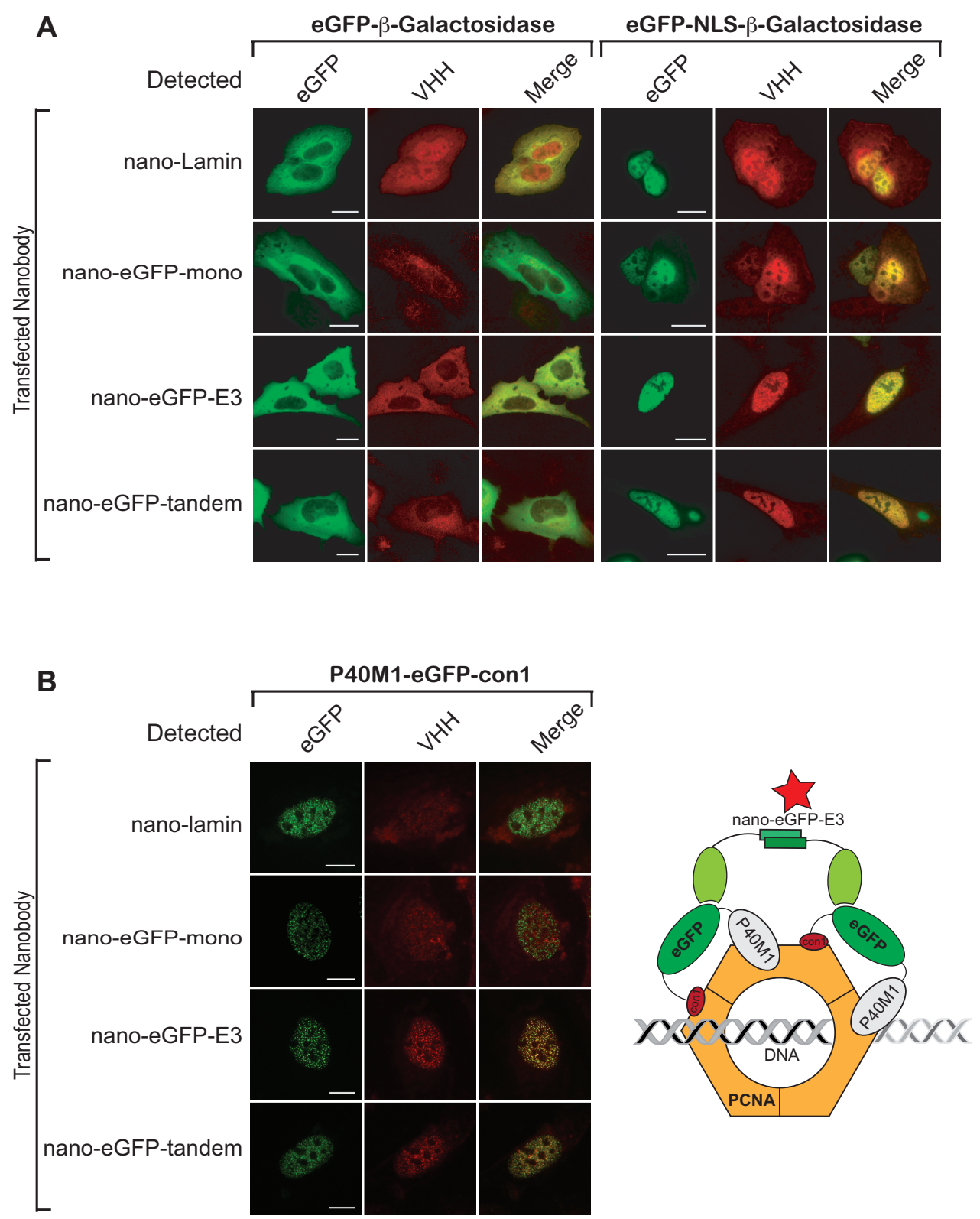

Figure 4. Binding recognition of various eGFP fusion proteins by anti-eGFP nanobodies A and B U2OS cells were transfected with various eGFP antigen expression vectors as indicated, together with nanobody expression plasmids. At $24 \mathrm{~h}$ post-transfection, cells were treated (P40M1-eGFP-con1) or not with CSK buffer (eGFP- $\beta$-Gal antigens), fixed, permeabilized and mounted. The proteins fused to eGFP were visualized by direct fluorescence and bound-nanobodies were detected by the anti-Myc 9E10 monoclonal antibody (mAb) followed by a labeled Alexa 568 anti-mouse. Scale bar, $10 \mu \mathrm{m}$.

Because transfection of expression plasmids drives an overload / excess of nanobody compared to the antigen, and because CSK treatment is not appropriate to eliminate unbound $\mathrm{V}_{\mathrm{H}} \mathrm{Hs}$ to freely mobile antigens, a second strategy consisting to directly electro-transfer the purified nanobodies was implemented. In that case, the nanobodies are generally present at lower levels than the target antigen.

For the H2B-eGFP antigen, the expression of the eGFP target antigen was high enough to titrate the three transduced nanobodies (Figure $5 \mathrm{~A}$ left panel). There were no 
obvious detection differences between the monovalent and the bivalent formats. These interactions were specific, as the nano-HER2 used as a negative control (Stoessel et al., 2020), did not bind to H2B-eGFP and thus localized in both cytoplasmic and nuclear compartments. For the MTS-eGFP localized in the mitochondria compartment, the transduced $\mathrm{V}_{\mathrm{H}} \mathrm{Hs}$ clearly co-localized with the eGFP signal except for the negative control nano-HER2, as expected (Figure 5A right panel). The nano-eGFP-mono led to higher background compared to the bivalent formats.

Lastly, the translesional DNA polymerase- $\eta$ fused to YFP (YFP-pol $\eta$ ) was also used as an antigen bound to the chromatin. The Poln plays a pivotal role to bypass replication arrest following DNA lesions induced by ultraviolet irradiation and thus accumulates at DNA foci through its direct interaction with PCNA. The YFP-poly expressing stable cell lines were electro-transferred with the three purified nanobodies (Figure 5B and $5 C$ ). Then, MRC5 cells were UV-irradiated $24 \mathrm{~h}$ after transfection and treated without or with CSK buffer $3 \mathrm{~h}$ later, before fixation. Without CSK treatment, the two bivalent $\mathrm{V}_{\mathrm{H}} \mathrm{Hs}$ were able to detect YFP-pol $\eta$, but a sharper signal was given by the nano-eGFP-E3 (Figure 5B). The nano-GFP-mono yielded to a high level of non-specific signals. After CSK treatment, the signals given by all nanobodies were better delineated because the excess of non-bound $\mathrm{V}_{\mathrm{H}} \mathrm{Hs}$ was washed out to reveal those tightly bound to YFP-poln (Figure 5B). Statistic analyzes demonstrate the superiority of both bivalent $\mathrm{V}_{\mathrm{H}} \mathrm{H}$ over the monovalent format (Figure $5 \mathrm{C}$ ). Indeed, around $85 \%$ of the YFP-poln foci signal co-localized with the signal of the nano-eGFP-E3, and $65 \%$ for the nano-eGFP-tandem, while less than $30 \%$ for the monovalent nano-eGFP-mono. The negative control nano-HER2 was not detecting YFP-poln, as expected. All together these results demonstrate the superiority of the bivalent formats compared to the monovalent counterpart. Moreover, the nano-GFP-E3 is in some cases better than the nano-eGFP-tandem, justifying the use of the small E3 peptide as dimerization device. 

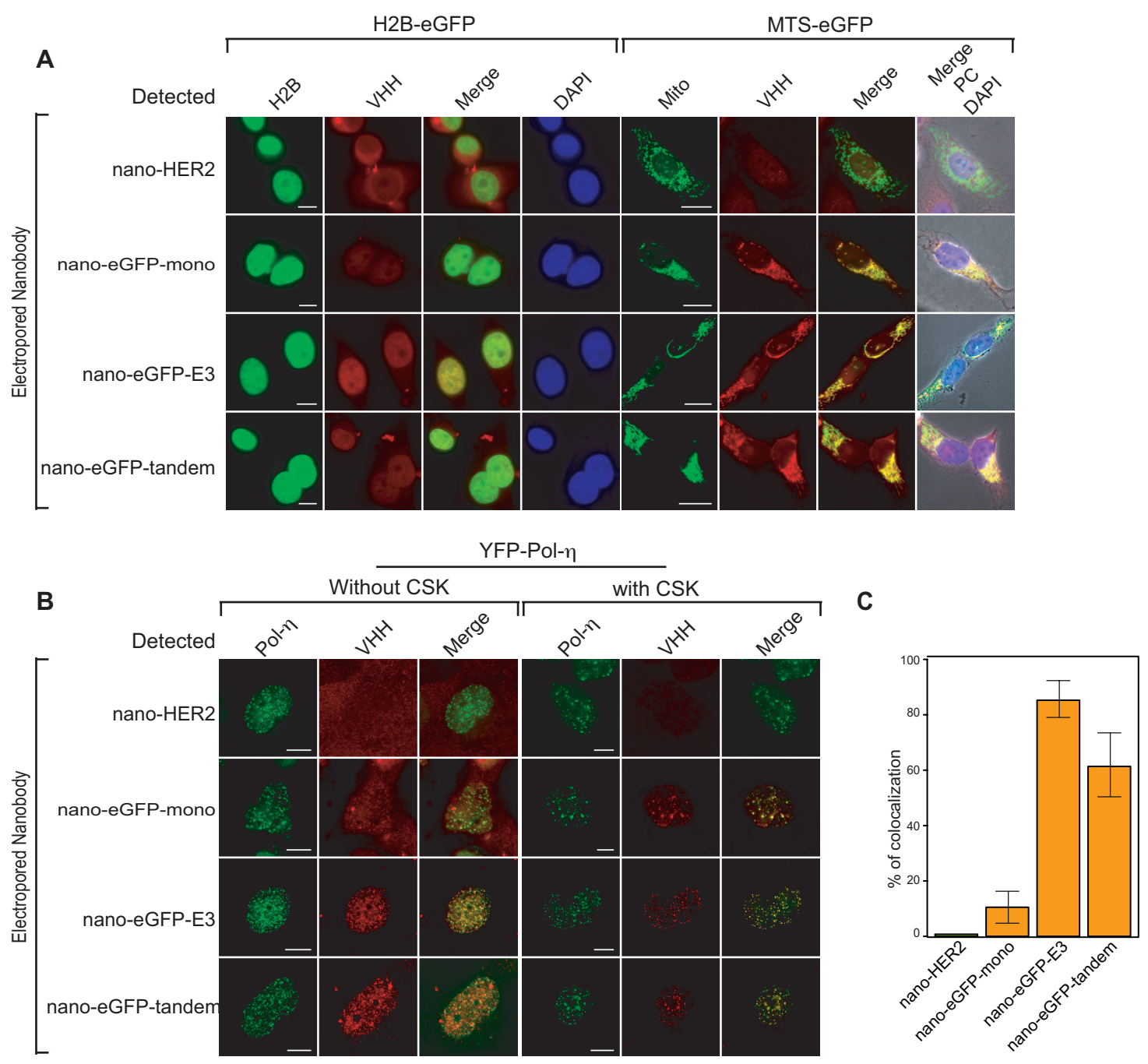

Figure 5. The purified nanobodies were directly electro-transfected in (A) H2B-eGFP cell line or together with the MTS-eGFP expression plasmid, and (B) in MRC5 stable cell line expressing YFP-poln. At $24 \mathrm{~h}$ post-transfection $(B)$ cells were treated with UV radiations and treated or not with CSK buffer, as indicated. Cells were fixed, permeabilized and mounted. The eGFP antigens were visualized by direct fluorescence (green) and nanobodies were detected by the anti-Myc 9E10 monoclonal antibody (mAb) followed by a labeled Alexa 568 anti-mouse (red). Nuclei were visualized by DAPI (blue). Images were taken by fluorescence microscopy and phase-contrast (PC). Scale bars, (A) $20 \mu \mathrm{m}$, and (B) $10 \mu \mathrm{m}$. (C) Statistic analysis were performed on MRC5 stable cell line expressing YFP-pol $\eta$ transduced with the nanobodies, as indicated, and after CSK treatment before cell fixation and permeabilization. 


\section{DISCUSSION}

For particular applications, bivalency might be advantageous or even required. For example, only low-nanomolar or subnanomolar range antibodies or antibody fragments can be used as successful imaging agents (Anna Orlova et al., 2007). Thus, bivalency is a simple way to increase affinity by means of avidity. $\mathrm{V}_{\mathrm{H}} \mathrm{Hs}$ are perfect building entities to achieve multivalent units. This can be achieved either by genetic fusion of $\mathrm{V}_{\mathrm{H}} \mathrm{H}$ open reading frames in tandem, by using dimerization domains, or by chemical conjugation. However, the formatting of bivalent $\mathrm{V}_{\mathrm{H}} \mathrm{Hs}$ is not strictly straightforward and each method has its advantages and drawbacks (Els Conrath et al., 2001).

Here, we report the use of a small peptide of 31 amino acid residues to engineer bivalent $\mathrm{V}_{\mathrm{H}} \mathrm{Hs}$. This peptide, E3, derives from the tetramerization domain of $\mathrm{p} 53$ and is capable to self-associate spontaneously into extremely stable homodimers. Indeed, the $K_{D}$ value of the E3 monomer-dimer equilibrium was evaluated to be lower than $10^{-15} \mathrm{M}$ (Brokx et al., 2003). In comparison, the $K_{D}$ of a small leucine zipper dimerization domain was shown to be of $2.510^{-7} \mathrm{M}$ (Moll et al., 2000). In addition, we have previously shown by Circular Dichroism that the unfolding state of the E3 construct after thermal denaturation was almost completely regenerated upon cooling, suggesting an important resilience of the secondary structures (Vigneron et al., 2019).

The fusion at the C-terminus of the anti-eGFP $\mathrm{V}_{\mathrm{H}} \mathrm{H}$ leading to a tail-to-tail orientation was evaluated against a fusion of the $\mathrm{V}_{\mathrm{H}} \mathrm{H}$ in tandem, with a tail-to-head orientation. If the ELISA and SPR results showed moderate gains of affinity, as compared to the monomeric parental $\mathrm{V}_{\mathrm{H}} \mathrm{H}$, this might be explained by the fact that the monomeric parental $\mathrm{V}_{\mathrm{H}} \mathrm{H}$ used in this study has already an extremely high affinity towards the eGFP $\left(K_{D}\right.$ of $0.32 \mathrm{nM}$ (Saerens et al., 2005)). Nevertheless, differences could be observed in SPR between the tandem and the dimeric format in terms of the maximal value of the normalized response $\left(R_{\text {norm }}\right)$. The $R_{\text {norm }}$ reached the maximal value of 1.00 for the nano-eGFP-E3, but only around 0.7 for the nanoeGFP-tandem. Thus, one can hypothesize that the second $\mathrm{V}_{\mathrm{H}} \mathrm{H}$ in the tandem construct has a slightly decrease of affinity for the eGFP. Indeed, in some cases, it has been observed that in tandem constructs, the $\mathrm{C}$-terminal $\mathrm{V}_{\mathrm{H}} \mathrm{H}$ exhibited slightly reduced on-rate properties than the $\mathrm{N}$-terminal moiety, leading to a reduced affinity (Els Conrath et al., 2001). For example, two bivalent versions on a $\mathrm{V}_{\mathrm{H}} \mathrm{H}$ directed against the scorpion toxin Aahl have been compared (Hmila et al., 2008), one construct correspond to a tandem $V_{H} H$ spaced by a 17 amino-acid peptide, and the other one correspond to the $\mathrm{V}_{\mathrm{H}} \mathrm{H}$ fused to the human $\operatorname{IgG} 1 \mathrm{CH} 2-\mathrm{CH} 3$ domain which spontaneously dimerises. The homodimer construct displayed an apparent dissociation constant of around 50 -fold better than the tandem $\mathrm{V}_{\mathrm{H}} \mathrm{H}$.

We also compared the binding activity of the three $\mathrm{V}_{\mathrm{H}} \mathrm{H}$ constructs on various eGFPfusion proteins localized in different cell compartments. For classical immunofluorescence on H2B-eGFP cell line, both bivalent were better at detecting the eGFP antigen than the monovalent format. However, only the nano-GFP-E3 was applicable at a concentration below 
$1 \mathrm{nM}$. For soluble eGFP fusion proteins, like eGFP- $\beta$-galactosidase, there were no noticeable differences between the monovalent and both bivalent $\mathrm{V}_{\mathrm{H}} \mathrm{Hs}$. In contrary, the detection of PCNA through the binding of the $\mathrm{V}_{\mathrm{H}} \mathrm{Hs}$ on the chimera fusion protein (P40M1-eGFP-con1) clearly showed the superiority of the bivalent formats over the monovalent counterpart. However, for soluble eGFP antigen such as MTS-eGFP directed to the mitochondrial compartment, the expression level of the nanobodies was to high to be titrated by the transiently expressed eGFP antigen. We could overcome this problem by electro-transferring the purified $\mathrm{V}_{\mathrm{H}} \mathrm{Hs}$ into the living cells. Again, all three nanobodies co-localized with the mitochondrial-expressed eGFP, with a slight better efficiency for both bivalent formats.

When analyzing the chromatin-bound eGFP polymerase $\eta$ fusion antigen, both bivalent formats were clearly betters compared to the monovalent counterpart. While $30 \%$ of nano-eGFP-mono co-localized with the antigen, more than $85 \%$ of the dimer E3 format was associated with the YFP-pol $\eta$ signal. One could notice that again, the nano-eGFP-E3 gave a clearer signal than the nano-eGFP-tandem.

\section{CONCLUSION}

This paper described a self-associating E3 peptide able to form spontaneously and remarkably stable homodimers in vitro and in living cells to engineer bivalent $\mathrm{V}_{\mathrm{H}} \mathrm{Hs}$ leading to tail-to-tail format. Because $\mathrm{V}_{\mathrm{H}} \mathrm{Hs}$ display unique properties, such as high solubility and a reversible unfolding reaction under stringent conditions (Muyldermans, 2013), E3 small peptide is of particular interest for dimerization of $\mathrm{V}_{\mathrm{H}} \mathrm{Hs}$. Indeed, we have previously reported that $\mathrm{E} 3$ peptide is robust at low $\mathrm{pH}$, form in complex media and resists thermal denaturation above $90^{\circ} \mathrm{C}$ (Stoessel et al., 2020; Vigneron et al., 2019), making it a powerful tool for bivalent $\mathrm{V}_{\mathrm{H}} \mathrm{Hs}$ engineering.

\section{Supporting Information Available}

DNA and proteins sequences, figures showing additional representations of the nanobodies, purification steps and SEC analysis of recombinants proteins, and immunofluorescence assays are given.

\section{ACKNOWLEDGEMENTS}

This work was supported by funds and/or fellowships from the Centre National de la Recherche Scientifique, the University of Strasbourg, the French Ministry of Research and the Ligue Régionale contre le Cancer (CCIR-GE), the Fondation ARC pour la recherche sur le cancer et ITI Innovec (IdEx (ANR-10-IDEX-0002) and SFRI (ANR-20-SFRI-0012). 
Anna Orlova, Joachim Feldwisch, Abrahmsen, L., Tolmachev, V., 2007. Affibody Molecules for Molecular Imaging and Therapy for Cancer. CANCER BIOTHERAPY

RADIOPHARMACEUTICALSVolume , Number , 1-12. doi:10.1089/cbr.2006.004-U

Baldeck, N., Janel-Bintz, R., Wagner, J., Tissier, A., Fuchs, R.P., Burkovics, P., Haracska, L., Despras, E., Bichara, M., Chatton, B., Cordonnier, A.M., 2015. FF483-484 motif of human Pol mediates its interaction with the POLD2 subunit of Pol and contributes to DNA damage tolerance. Nucleic Acids Research 43, 2116-2125. doi:10.1093/nar/gkv076

Beirnaert, E., Desmyter, A., Spinelli, S., Lauwereys, M., Aarden, L., Dreier, T., Loris, R., Silence, K., Pollet, C., Cambillau, C., de Haard, H., 2017. Bivalent Llama Single-Domain Antibody Fragments against Tumor Necrosis Factor Have Picomolar Potencies due to Intramolecular Interactions. Front. Immunol. 8, 41. doi:10.1124/jpet.301.2.418

Bonhoure, A., Demenge, A., Kostmann, C., José, L.S., la Cal, De, E., Armisen, P., Nominé, Y., Travé, G., 2018. One-step affinity purification of fusionproteins with optimal monodispersityand biological activity: applicationto aggregation-prone HPV E6 proteins. Microb Cell Fact 1-14. doi:10.1186/s12934-018-1039-z

Brokx, R.D., Bolewska-Pedyczak, E., Gariépy, J., 2003. A Stable Human p53 Heterotetramer Based on Constructive Charge Interactions within the Tetramerization Domain. J Biol Chem 278, 2327-2332. doi:10.1093/nar/22.22.4673

Cardoso, F.M., Ibanez, L.I., Van den Hoecke, S., De Baets, S., Smet, A., Roose, K., Schepens, B., Descamps, F.J., Fiers, W., Muyldermans, S., Depicker, A., Saelens, X., 2014. Single-Domain Antibodies Targeting Neuraminidase Protect against an H5N1 Influenza Virus Challenge. J Virol 88, 8278-8296. doi:10.1111/pbi.12094

Coppieters, K., Dreier, T., Silence, K., Haard, H.D., Lauwereys, M., Casteels, P., Beirnaert, E., Jonckheere, H., Wiele, C.V.D., Staelens, L., Hostens, J., Revets, H., Remaut, E., Elewaut, D., Rottiers, P., 2006. Formatted anti-tumor necrosis factor a VHH proteins derived from camelids show superior potency and targeting to inflamed joints in a murine model of collagen-induced arthritis. Arthritis Rheum 54, 1856-1866. doi:10.1002/ijc.10212

De Meyer, T., Muyldermans, S., Depicker, A., 2014. Nanobody-based products as research and diagnostic tools 1-8. doi:10.1016/j.tibtech.2014.03.001

De Vlieger, D., Ballegeer, M., Rossey, I., Schepens, B., Saelens, X., 2019. Single-Domain Antibodies and Their Formatting to Combat Viral Infections. Antibodies 8, 1. doi:10.1002/emmm.201201379

Donzeau, M., Knappik, A., 2007. Recombinant monoclonal antibodies. Methods Mol Biol 378, 14-31.

Dumoulin, M., Conrath, K., Van Meirhaeghe, A., Meersman, F., Heremans, K., Frenken, L.G.J., Muyldermans, S., Wyns, L., Matagne, A., 2002. Single-domain antibody fragments with high conformational stability. Protein Sci. 11, 500-515. doi:10.1110/ps.34602

Els Conrath, K., Lauwereys, M., Wyns, L., Muyldermans, S., 2001. Camel Single-domain Antibodies as Modular Building Units in Bispecific and Bivalent Antibody Constructs. J Biol Chem 276, 7346-7350. doi:10.1016/S0168-1656(99)00228-X

Freund, G., Desplancq, D., Stoessel, A., Weinsanto, R., Sibler, A.-P., Robin, G., Martineau, P., Didier, P., Wagner, J., Weiss, E., 2014. Generation of an intrabody-based reagent suitable for imaging endogenous proliferating cell nuclear antigen in living cancer cells. J. Mol. Recognit. 27, 549-558. doi:10.1002/jmr.2378

Freund, G., Sibler, A.-P., Desplancq, D., Oulad-Abdelghani, M., Vigneron, M., Gannon, J., Van Regenmortel, M.H., Weiss, E., 2013. Targeting endogenous nuclear antigens by electrotransfer of monoclonal antibodies in living cells. mabs $5,518-522$. doi:10.4161/mabs.25084

Hmila, I., Abdallah R, B.A.-B., Saerens, D., Benlasfar, Z., Conrath, K., Ayeb, M.E., Muyldermans, S., Bouhaouala-Zahar, B., 2008. VHH, bivalent domains and chimeric Heavy chain-only antibodies with high neutralizing efficacy for scorpion toxin Aahl'. Molecular Immunology 45, 3847-3856. doi:10.1016/j.molimm.2008.04.011

Hultberg, A., Temperton, N.J., Rosseels, V., Koenders, M., Gonzalez-Pajuelo, M., Schepens, B., Ibañez, L.I., Vanlandschoot, P., Schillemans, J., Saunders, M., Weiss, R.A., Saelens, X., Melero, J.A., Verrips, C.T., Van Gucht, S., de Haard, H.J., 2011. Llama-Derived Single Domain Antibodies to Build Multivalent, Superpotent and Broadened Neutralizing AntiViral Molecules. PLoS ONE 6, e17665. doi:10.1371/journal.pone.0017665.t005 
Jeffrey, P.D., Gorina, S., Pavletich, N.P., 1995. Crystal structure of the tetramerization domain of the p53 tumor suppressor at 1.7 angstroms. Science 267, 1498-1502.

Karlsson, R., Roos, H., Bruno, J., Stolz, L., 1997. Practical aspects concerning direct detection of low molecular weight analytes using BIACORE. methodology 1-3.

Klooster, R., Eman, M.R., le Duc, Q., Verheesen, P., Verrips, C.T., Roovers, R.C., Post, J.A., 2009. Selection and characterization of KDEL-specific VHH antibody fragments and their application in the study of ER resident protein expression. J Immunol Methods 342, 1-12. doi:10.1016/j.jim.2008.10.009

Masson, M., Hindelang, C., Sibler, A.-P., Schwalbach, G., Travé, G., Weiss, E., 2003. Preferential nuclear localization of the human papillomavirus type $16 \mathrm{E} 6$ oncoprotein in cervical carcinoma cells. J. Gen. Virol. 84, 2099-2104. doi:10.1099/vir.0.18961-0

Moldovan, G.-L., Pfander, B., Jentsch, S., 2007. PCNA, the Maestro of the Replication Fork. Cell 129, 665-679. doi:10.1016/j.cell.2007.05.003

Moll, J.R., Ruvinov, S.B., Pastan, I., vinson, C., n.d. Designed heterodimerizing leucine zippers with a range of pls and stabilities up to $10-15$ M. protein science. 2000. 10, 649:655.

Muyldermans, S., 2013. Nanobodies: natural single-domain antibodies. Annu. Rev. Biochem. 82, 775-797. doi:10.1146/annurev-biochem-063011-092449

Pack, P., Knappik, A., Krebber, C., Plückthun, A., 1992. Monoand Bivalent Antibody Fragments Produced in E. coli: Binding Properties and Folding in vivo. ACS Conferences Proccedings series 10-13.

Rheinnecker, M., Hardt, C., Ilag, L.L., Kufer, P., Gruber, R., Hoess, A., Lupas, A., Rottenberger, C., Plückthun, A., Pack, P., 1996. Multivalent antibody fragments with high functional affinity for a tumor-associated carbohydrate antigen. J. Immunol. 157, 29892997.

Rothbauer, U., Zolghadr, K., Tillib, S., Nowak, D., Schermelleh, L., Gahl, A., Backmann, N., Conrath, K., Muyldermans, S., Cardoso, M.C., Leonhardt, H., 2006. Targeting and tracing antigens in live cells with fluorescent nanobodies. Nat Methods 3, 887-889. doi:10.1016/S0014-5793(97)01062-4

Saerens, D., GHASSABEH, G., Muyldermans, S., 2008. Single-domain antibodies as building blocks for novel therapeutics. Current Opinion in Pharmacology 8, 600-608. doi:10.1016/j.coph.2008.07.006

Saerens, D., Pellis, M., Loris, R., Pardon, E., Dumoulin, M., Matagne, A., Wyns, L., Muyldermans, S., Conrath, K., 2005. Identification of a universal VHH framework to graft non-canonical antigen-binding loops of camel single-domain antibodies. J Mol Biol 352, 597-607. doi:10.1016/j.jmb.2005.07.038

Shima, D.T., Haldar, K., Pepperkok, R., Watson, R., Warren, G., 1997. Partitioning of the Golgi apparatus during mitosis in living HeLa cells. J Cell Biol 137, 1211-1228. doi:10.1083/jcb.137.6.1211

Stoessel, A., Groysbeck, N., Guyot, L., Barret, L., Nominé, Y., Nguekeu-Zebaze, L., Bender, A., Voilquin, L., Lutz, T., Pallaoro, N., Blocat, M., Deville, C., Masson, M., Zuber, G., Chatton, B., Donzeau, M., 2020. Modular Conjugation of a Potent Anti-HER2 Immunotoxin Using Coassociating Peptides. Bioconjugate Chem. 31, 2421-2430. doi:10.1021/acs.bioconjchem.0c00482

Syedbasha, M., Linnik, J., Santer, D., O'Shea, D., Barakat, K., Joyce, M., Khanna, N., Tyrrell, D.L., Houghton, M., Egli, A., 2016. An ELISA Based Binding and Competition Method to Rapidly Determine Ligand-receptor Interactions. JoVE 1-10. doi:10.3791/53575

van Lith, S.A.M., van Duijnhoven, S.M.J., Navis, A.C., Leenders, W.P.J., Dolk, E., Wennink, J.W.H., van Nostrum, C.F., van Hest, J.C.M., 2017. Legomedicine-A Versatile ChemoEnzymatic Approach for the Preparation of Targeted Dual-Labeled Llama AntibodyNanoparticle Conjugates. Bioconjugate Chem. 28, 539-548. doi:10.1021/acs.bioconjchem.6b00638

Vigneron, M., Dietsch, F., Bianchetti, L., Dejaegere, A., Nominé, Y., Cordonnier, A., Zuber, G., Chatton, B., Donzeau, M., 2019. Self-Associating Peptides for Modular Bifunctional Conjugation of Tetramer Macromolecules in Living Cells. Bioconjugate Chem. 30, 17341744. doi:10.1021/acs.bioconjchem.9b00276 